\title{
Proceeding
}

7th INSHS International Christmas Sport Scientific Conference, 9-12 December 2012. International Network of Sport and Health

Science. Szombathely, Hungary

\section{The comparison of flexibility in the Czech population aged $18-59$ years}

\author{
EDUARD HRAZDÍRA , PAVEL GRASGRUBER, TOMÁŠ KALINA \\ Faculty of Sports Studies, Masaryk University, Brno, Czech Republic
}

\begin{abstract}
Hrazdíra E, Grasgruber P, Kalina T. The comparison of flexibility in the Czech population aged 18-59 years. J. Hum. Sport Exerc. Vol. 8, No. Proc2, pp. S135-S140, 2013. The aim of this study was to compare flexibility in the Czech population in age 18 - 59. The values of isometric strength were obtained using a sit and reach test (measuring of maximal reach in sit). In comparison with previous standards of sit-and-rech test are our results higher than average. Higher level of flexibility reach women, sporting people and younger age. The most decreasing flexibility was described among young men. The reached results are affected by body characteristics, mainly by obesity degrese and waist-to-hit ratio.Key words: FLEXIBILITY TESTING, SIT AND REACH, MOVEMENT ACTIVITY.
\end{abstract}

\footnotetext{
Corresponding author. Kamenice 5. 62500 Brno. Czech Republic.

E-mail: hrazdira@fsps.muni.cz

7th INSHS International Christmas Sport Scientific Conference, 9-12 December 2012. International Network of Sport and Health Science. Szombathely, Hungary.

JOURNAL OF HUMAN SPORT \& EXERCISE ISSN 1988-5202

(c) Faculty of Education. University of Alicante

doi:10.4100/jhse.2012.8.Proc2.17
} 


\section{INTRODUCTION}

Flexibility is seen rather as an attribute of the musculoskeletal system; in more recent publications it is connected with passive systems of energy transfer. The structure of flexibility still isn't unified; for diagnostic purposes in sport, there exists an accepted division into a general and special, active and passive, static and dynamic flexibility, or joint mobility and the ability to stretch.

Flexibility can be characterized as:

- "The ability to perform the motion in the appropriate extent, in the full amplitude" (Měkota \& Novosad, 2005).

- "The prerequisite for a sufficiently large amplitude of the joint deflection during movement or during preoccupation with certain positions" (Schnabel et al., 1994).

- "The ability to perform an intentional movement with a large range in the respective joint" (Grosser \& Zintl, 1994).

- "The ability to deliberately and purposefully perform functional joint movements with the necessary or optimal range in the respective joint" (Roth \& Willimczik, 1999).

Authors K. F. Wells and E.K. Dillon were among the first researchers, who developed tests of flexibility. They described their "sit-and-reach test" in their publication The sit and reach. A test of back and leg flexibility (1952). This test can be used for the measurement of flexibility in the area of the lumbar spine and the back part of the thigh. Up to now, there has been a number of variants of this test of flexibility. The main differences lie in the position of the feet to the measuring device (with either both or only one leg leaning towards the desk) and the location of the zero point on the top of the measuring desk. The most natural way of measuring is with the zero point at the level of the feet. In case the tested person can't reach it, its performance is recorded with a minus sign. However, the use of negative values is inappropriate for the statistical comparison of results. At present, we therefore often encounter a variant of the sit-and-reach test, where the zero point exceeds the feet. The most common versions of the test use either a 15 or $25 \mathrm{~cm}$ overlap (Figure 1).

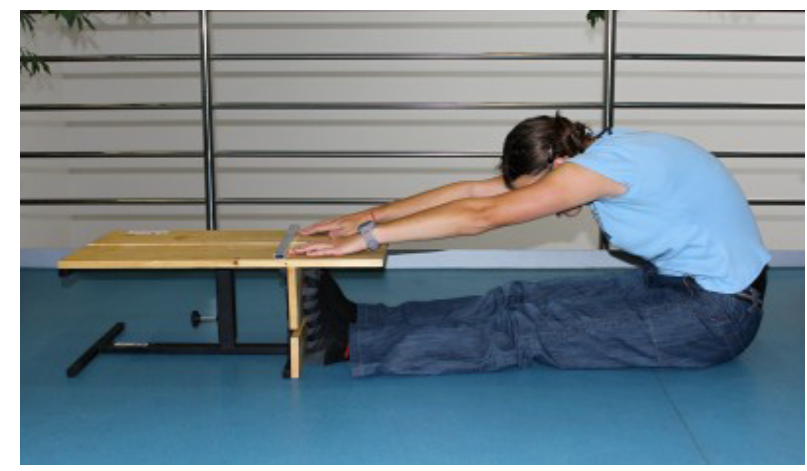

Figure 1. The sit-and-reach test with an overlap over the zero point. 
The objective of this research is to compare flexibility in selected age groups of men and women of the Czech Republic via the sit-and-reach test. Further, we will investigate the influence of some bodily characterics on the performance in the test.

\section{MATERIAL AND METHODS}

The tested sample included 843 individuals from the Czech Republic, 18-59 years old, divided into 4 age categories. Out of this number, 840 responded to questions concerning their level of physical activity (Table 1).

Table 1. The number of measured individuals in each age category.

\begin{tabular}{cccc} 
Age Category & Age Range & Measured Subjects & $\begin{array}{c}\text { Subjects that } \\
\text { responded to a } \\
\text { questionnaire }\end{array}$ \\
\hline 1 & $18-29$ & 287 & 284 \\
2 & $30-39$ & 256 & 256 \\
3 & $40-49$ & 199 & 199 \\
4 & $50-59$ & 101 & 101 \\
\hline
\end{tabular}

For the measurement of flexibility in the sit-and-reach test, we use a board having these dimensions: length $75 \mathrm{~cm}$, width $40 \mathrm{~cm}$, variable height. The feet touch a vertical board is positioned $20 \mathrm{~cm}$ from the margin of the top board (see Figure 1). The top board is marked with a scale from -5 to $70 \mathrm{~cm}$. The scale has a $15 \mathrm{~cm}$ overlap, and another $5 \mathrm{~cm}$ is added to measure occasional negative results. The tested subject gradually leans his forearms forward on the top board. He must hold in the extreme position for at least 2 seconds. The test is repeated three-times. The best result is recorded.

The results were obtained in the period August 2011 - September 2012. Measurement was carried out under the project, which is concerned with detecting the level of physical activity of the population of the Czech Republic (CZ.1.07/2.3.00/20.0044).

\section{RESULTS AND DISCUSSION}

The sample of 388 men achieved an average score $21.98 \mathrm{~cm}$, which corresponds to the absolute performance of $6.98 \mathrm{~cm}$. The sample of 455 women achieved $27.29 \mathrm{~cm}$ (absolute performance $+12.29 \mathrm{~cm}$ ). These values are entirely satisfactory in terms of the recommended standards. The results confirmed that women consistently perform better than men. Gender differences were highly statistically significant $(p<0.01)$. The documented data also show that flexibility in both men and women progressively decreases with increasing age (Table 2, Figure 2). This decrease is a markedly steeper in men, reaching statistical significance in the progression from 1 to 2 age category $(p<0.05)$. In women, a significant decrease was observed between age categories 1 and $4(p=0.03)$. Overall, our subjects achieved average to aboveaverage results according to above mentioned standards. 
Table 2. Performances of men and women in the sit-and-reach test, according to age category.

\begin{tabular}{|c|c|c|c|c|c|c|c|}
\hline \multicolumn{2}{|c|}{ Age cat. } & \multirow{2}{*}{$\begin{array}{l}\text { Gender } \\
\text { Men }\end{array}$} & \multirow{2}{*}{$\begin{array}{c}\begin{array}{c}\text { Average } \\
\text { performance }\end{array} \\
25.36\end{array}$} & \multirow{2}{*}{$\begin{array}{c}\text { Standard Error } \\
0.75\end{array}$} & \multirow{2}{*}{$\begin{array}{c}\text { Confidence } \\
\text { interval } \\
-95 \% \\
23.88\end{array}$} & \multirow{2}{*}{$\begin{array}{c}\begin{array}{c}\text { Confidence } \\
\text { interval } \\
+95 \%\end{array} \\
26.84\end{array}$} & \multirow{2}{*}{$\frac{N}{144}$} \\
\hline 1 & $18-29$ & & & & & & \\
\hline 1 & $18-29$ & Women & 28.64 & 0.76 & 27.16 & 30.13 & 143 \\
\hline 2 & $30-39$ & Men & 21.21 & 0.86 & 19.52 & 22.89 & 111 \\
\hline 2 & $30-39$ & Women & 27.84 & 0.75 & 26.37 & 29.32 & 145 \\
\hline 3 & $40-49$ & Men & 21.08 & 0.96 & 19.21 & 22.97 & 89 \\
\hline 3 & $40-49$ & Women & 27.25 & 0.86 & 25.56 & 28.94 & 110 \\
\hline 4 & $50-59$ & Men & 20.26 & 1.36 & 17.58 & 22.94 & 44 \\
\hline 4 & $50-59$ & Women & 25.43 & 1.19 & 23.08 & 27.78 & 57 \\
\hline
\end{tabular}

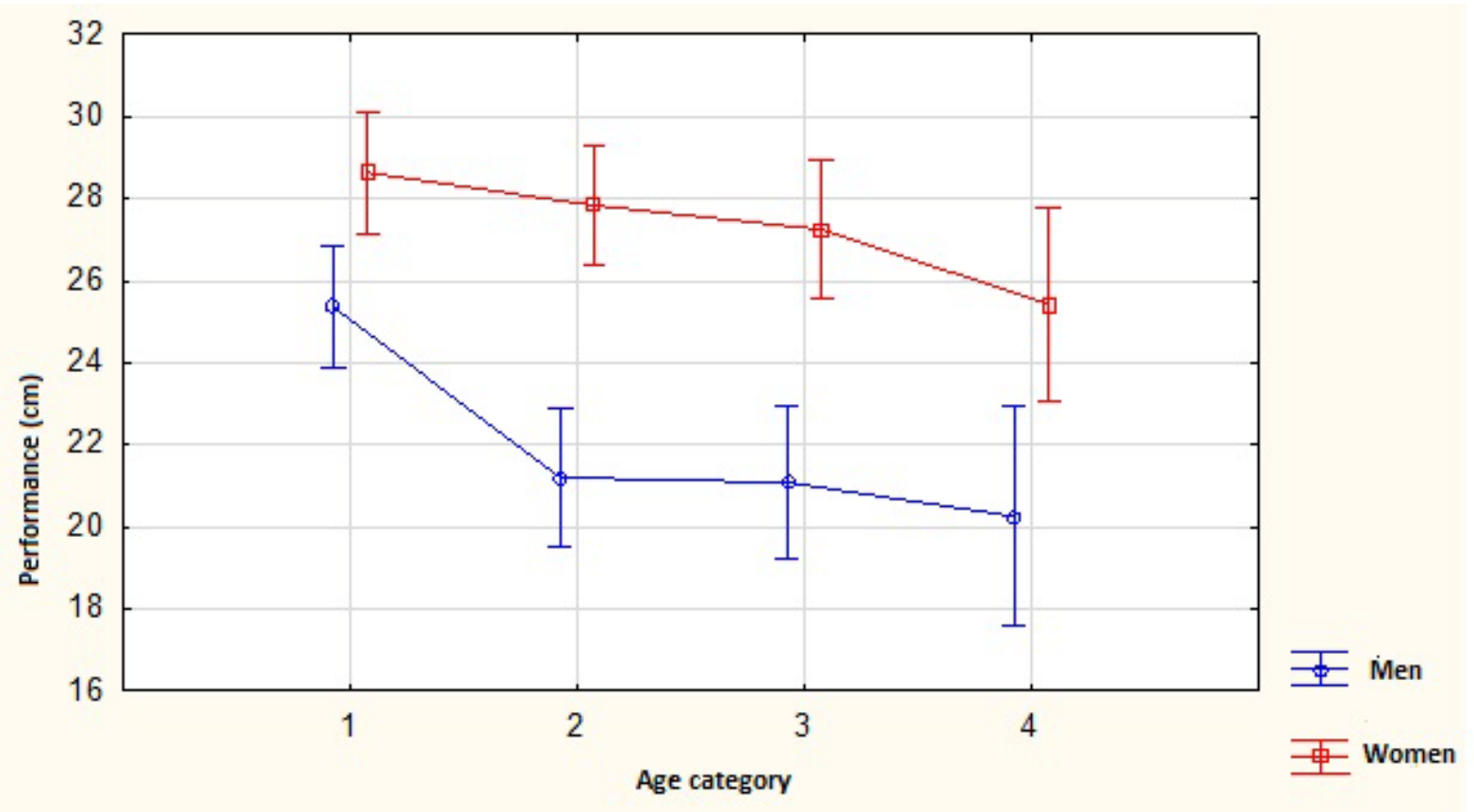

Figure 2. Performances of men and women in the sit-and-reach test, according to age group.

Relationship between performance in the sit-and-reach test and the level of physical activity.

Besides differences by gender and age, we also studied the influence of physical activity on the level of flexibility. The results show that physically inactive men in categories 3 and 4 achieved a marginally better performance than physically active men $(22.03$ vs. $20.89 \mathrm{~cm}$ and $21.30 \mathrm{vs} .19 .99 \mathrm{~cm})$. Also, physically inactive women in the category 2 were slightly better than physically active women $(28.13 \mathrm{vs} .27 .80 \mathrm{~cm})$. Individuals in the category A (physically inactive) are generally characterized by considerable variance of performances. Therefore, differences between groups A and B in the same age category were never significantly different. See Figure 3. 


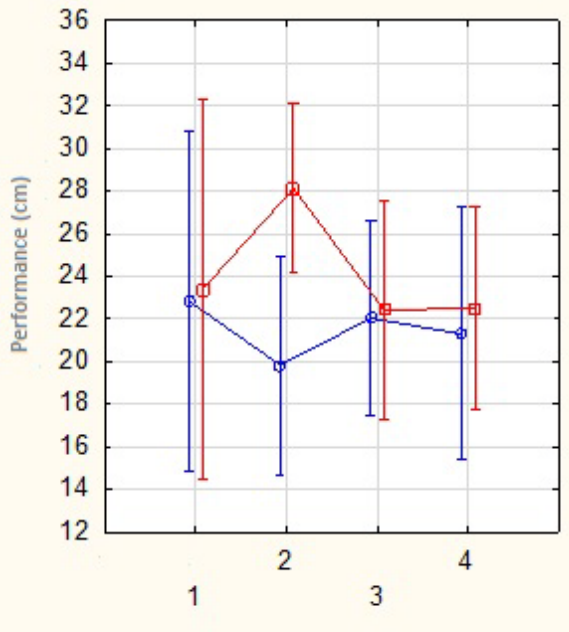

d9: A

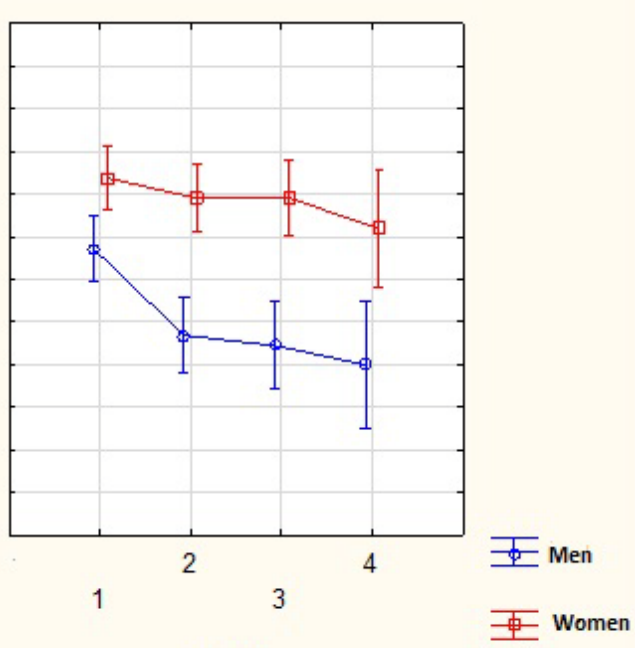

d9: B

Figure 3. Performances of men and women in the sit-and-reach test, according to the level of physical activity and age group.

Relationship between performance in the sit-and-reach test and physical characteristics.

Because performances in the sit-and-reach test may be influenced by physical factors such as length of limbs and obesity, we also examined a relationship with the relative sitting height, WHR index (the waist-tohip ratio) and \% body fat.

In the case of relative sitting height, there was a statistically positive relationship $(p<0.05)$ between the performance in the sit-and-reach test and relative sitting height, both in men and women. It is obvious that the larger relative length of the trunk allows better performances, which leads to distortion of results of body flexibility.

In the case of BMI, we again documented a statistically significant negative relationship with the performance $(p<0.05)$, in both sexes. Obesity and the associated accumulation of fat in the abdomen is a very important limiting factor in the sit-and-reach test, especially at values above $32 \mathrm{~kg} / \mathrm{m}^{2}$ and in men, whose fat is concentrated in the abdominal area more than in females.

Even index WHR (waist-to-hip ratio) negatively correlated with the performance at the level of statistical significance. It is clear that persons with a slimmer waist achieve better performance.

\section{CONCLUSIONS}

Generally speaking, we can say that men and women in this study achieved above-average results by the standards of the sit-and-reach test. Women are consistently more flexible than men of the same age. On average, physically active people have a higher level of flexibility than physically inactive individuals. In this case, however, we can not talk about a clear trend that would be valid in all age groups, perhaps also due to the very small number of subjects in the category of physically inactive people. Our study also shows that the results of the sit-and-reach test are significantly influenced by physical characteristics such as body proportions and the degree of obesity. 


\section{REFERENCES}

1. GROSSER M, ZINTL F. Training Der Konditionellen Fähigkeiten. 157s. Hofmann, Schorndorf. 1994.

2. MĚKOTA K, NOVOSAD J. Motorické schopnosti. 1. vyd., 175s., Olomouc: Univerzita Palackého v Olomouci. 2005.

3. ROTH K, WILLIMCZIK K. Bewegungswissenschaft. Rowohlt. 330s. 1999

4. SCHNABEL G. Trainingswissenschaft: Leistung, Training, Wettkampf. (3. stark überarbeitete und erweiterte Aufl., 528s.). München: Sportverlag Berlin. 2003. 